\title{
QUALIDADE FISIOLÓGICA DE SEMENTES DE Crataeva tapia L. SUBMETIDAS A DIFERENTES MÉTODOS DE EXTRAÇÃO DA MUCILAGEM ${ }^{1}$
}

\author{
SUELI DA SILVA SANTOS-MOURA ${ }^{2}$, EDNA URSULINO ALVES ${ }^{3}$, EVIO ALVES GALINDO², \\ MÁCIO FARIAS DE MOURA ${ }^{4}$, PAULO ALEXANDRE FERNANDES RODRIGUES DE MELO
}

RESUMO - Crataeva tapia L. é uma frutífera nativa, de copa arredondada e densa, cujos frutos comestíveis são ingeridos como refresco e bebida vinosa; além disso, possui características medicinais, ecológicas e econômicas pelo uso de sua madeira. Assim, objetivou-se avaliar a qualidade fisiológica de suas sementes quando submetidas a diferentes métodos de extração da mucilagem. Para tanto, foram testados os seguintes tratamentos: sementes com mucilagem - testemunha $\left(\mathrm{T}_{1}\right)$, fricção das sementes em cal virgem, pó de madeira e areia $\left(\mathrm{T}_{2}, \mathrm{~T}_{3}\right.$ e $\mathrm{T}_{4}$, respectivamente), sementes com mucilagem secas ao sol e lavadas em água com fricção em peneira $\left(\mathrm{T}_{5}\right.$ e $\mathrm{T}_{6}$, respectivamente) e fermentação em água por 24; 48; 72 e 96 horas $\left(\mathrm{T}_{7}\right.$, $\mathrm{T}_{8}, \mathrm{~T}_{9}, \mathrm{~T}_{10}$, respectivamente). Após a realização dos métodos de remoção da mucilagem, as sementes foram submetidas à determinação do teor de água e a testes de germinação e vigor (primeira contagem e índice de velocidade de germinação, comprimento e massa seca de plântulas), cujo delineamento foi inteiramente ao acaso. Pelos resultados obtidos, verificou-se que o teor de água das sementes submetidas aos métodos de extração da mucilagem reduziu, sendo mais elevado nas sementes lavadas em água com fricção em peneira e na testemunha. Os métodos de extração com pó de madeira e fermentação, por 48 e 72 horas $\left(\mathrm{T}_{3}, \mathrm{~T}_{8}\right.$ e $\mathrm{T}_{9}$, respectivamente), promovem as maiores porcentagens de germinação, sendo que os melhores resultados de vigor foram verificados nos tratamentos de fricção das sementes em pó de madeira e fermentação por 48 horas $\left(\mathrm{T}_{3}\right.$ e $\mathrm{T}_{8}$, respectivamente).

Termos para indexação: tapiá, frutífera nativa, viabilidade, vigor.

\section{PHYSIOLOGICAL QUALITY OF Crataeva tapia L. SEEDS UNDER DIFFERENT MUCILAGE EXTRACTION METHODS}

\begin{abstract}
Crataeva tapia L. is a native fruit, with dense rounded crown, whose edible fruits are ingested just as refreshment vinous beverage also has medicinal properties, ecological and economical use of the wood. Thus the objective was to evaluate the physiological quality of their seeds exposed to different extraction methods of mucilage. For both tested the following treatments: seeds with mucilage - control $\left(\mathrm{T}_{1}\right)$, rubbing the seeds in lime, wood dust and sand $\left(\mathrm{T}_{2}, \mathrm{~T}_{3}\right.$ and $\mathrm{T}_{4}$, respectively), seed with mucilage sundried and washed with water friction strainer $\left(\mathrm{T}_{5}\right.$ and $\mathrm{T}_{6}$, respectively) and fermentation in water for 24,48 , 72 and 96 hours $\left(\mathrm{T}_{7}, \mathrm{~T}_{8}, \mathrm{~T}_{9}, \mathrm{~T}_{10}\right.$, respectively). After performing the removing mucilage methods the seeds were submitted to the determination of the moisture content and the germination and vigor (first count and germination speed index, length and seedling dry weight), whose design was completely at random. The results obtained showed that the moisture content of seeds submitted to extraction mucilage methods reduced, being higher in seeds rinsed in water with rubbing strainer and control. The extraction methods with wood dust and fermentation for 48 and 72 hours $\left(\mathrm{T}_{3}, \mathrm{~T}_{8}\right.$ and $\mathrm{T}_{9}$, respectively) promote the highest germination, and the best results were achieved in the treatments of seed friction in wood dust and fermentation for 48 hours $\left(\mathrm{T}_{3}\right.$ and $\mathrm{T}_{8}$, respectively).
\end{abstract}

Index terms - Tapia, native fruit, viability, vigor.

\footnotetext{
'(Trabalho 133-13). Recebido em: 03-04-2013. Aceito para publicação em: 27-04-2014.

${ }^{2}$ Pós-Graduação em Agronomia, Departamento de Fitotecnia e Ciências Ambientais, Centro de Ciências Agrárias da Universidade Federal da Paraíba (CCA-UFPB). CEP: 58.397-000, Areia - PB. E-mails: suelidasilvasantos@yahoo.com.br; eviogalindoea@hotmail.com; pauloalexandre4.4@hotmail.com.

${ }^{3}$ Profa. Dra. do DFCA/CCA/UFPB, Campus II, Areia - PB. E-mail: ednaursulino@cca.ufpb.br.

${ }^{4}$ Prof. Dr. da UFRPE/UAG, Garanhuns - PE. E-mail: maciof@yahoo.com.br.
} 


\section{INTRODUÇ̃̃O}

No Brasil, existe grande variedade de árvores frutíferas nativas ainda pouco estudadas, muitas com potencial de aproveitamento pouco explorado devido à falta de estudos que permitam a implantação de pomares comerciais, pois a limitação de seu uso é em função da carência de informações técnicas sobre o manejo de suas sementes (KOHAMA et al., 2006). Muitas destas espécies têm as sementes envolvidas por uma mucilagem de difícil remoção, a qual pode prejudicar a germinação e o crescimento das plântulas por favorecer o desenvolvimento de microrganismos ou conter substâncias inibidoras de germinação (CARMONA et al., 1994).

Dentre as espécies com sementes envolvidas por mucilagem, destaca-se a Crataeva tapia L., da família Caparidacea, que é conhecida popularmente como trapiá, cabaceira, pau-de-alho, entre outros, a qual é uma frutífera nativa, cujos frutos são comestíveis, ingeridos como refresco e bebida vinosa (LORENZI, 2002), além de serem muito apreciados por pássaros e roedores, sendo suas flores apícolas. A árvore possui atributos ornamentais recomendáveis para arborização paisagística, para uso na recuperação de áreas degradas e para enriquecer capoeiras e vegetação nativa empobrecida (PRATISSOLI et al., 2007).

Nos frutos suculentos, substâncias tais como: suberina, cumarina, cutina, tanino e pectina, quando em concentração nas camadas do fruto ou em tecidos que recobrem as sementes, podem inibir o processo germinativo das sementes (CARVALHO; NAKAGAWA, 2012). No extrato de arilo de sementes de maracujá-amarelo (Passiflora edulis f.flavicarpa Deg.), a presença de substâncias inibidoras da germinação, tais como: esteroides, triterpenoides, açúcares redutores, interferiram direta ou indiretamente na absorção de água (MARTINS et al., 2010). Em outra espécie de maracujá-doce (Passiflora alata Curtis), obtiveram melhor emergência de plântulas $(62 ; 60,5$ e 57,75 $\%$ ), respectivamente, quando foi removido o arilo mediante fricção em malha de arame com areia, imersão em solução com cal ou ácido clorídrico, ambos com agitação por trinta minutos (OSIPI et al., 2011).

Para a determinação de melhor método para cada espécie em estudo, Alves et al. (2009) e Freitas et al. (2011) recomendam os seguintes tratamentos: fermentação natural, processos mecânicos ou químicos e, ainda, métodos manuais com a utilização de materiais abrasivos, tais como: areia, pó de madeira, cal virgem, fricção em peneira, entre outros.
O processo de fermentação tem sido um dos métodos mais empregados, sendo muito eficiente na remoção da mucilagem em diversas espécies, tais como: em sementes de Talisia esculenta Radlk (pitomba) com a fermentação de até 105 horas (ALVES et al., 2009); em sementes de Hylocereus undatus Haw, conhecida como pitaia-vermelha, o tratamento de imersão em solução de $\mathrm{HCl}$, durante uma hora, proporcionou $92 \%$ de germinação e $79 \%$ de vigor (ALVES et al., 2012).

Para a espécie frutífera Crataeva tapia L., foi realizado o presente trabalho com objetivo de avaliar a qualidade fisiológica das sementes que foram submetidas a diferentes tratamentos e métodos de extração da mucilagem.

\section{MATERIAL E MÉTODOS}

O trabalho foi conduzido no Laboratório de Análise de Sementes (LAS) do Departamento de Fitotecnia e Ciências Ambientais, do Centro de Ciências Agrárias da Universidade Federal da Paraíba, cujos frutos foram coletados em matrizes localizadas na cidade de Remígio - PB. No LAS, foi realizado o beneficiamento de forma manual, com abertura dos frutos e extração das sementes.

Após o beneficiamento, para a remoção da mucilagem, as sementes foram submetidas aos seguintes tratamentos: sementes com mucilagem - testemunha $\left(\mathrm{T}_{1}\right)$; fricção das sementes em cal virgem, pó de madeira e areia $\left(\mathrm{T}_{2}, \mathrm{~T}_{3}\right.$ e $\mathrm{T}_{4}$, respectivamente); sementes com mucilagem secas ao sol e lavadas em água com fricção em peneira ( $\mathrm{T}_{5}$ e $\mathrm{T}_{6}$, respectivamente), e fermentação em água por 24; 48; 72 e 96 horas $\left(\mathrm{T}_{7}, \mathrm{~T}_{8}, \mathrm{~T}_{9}\right.$ e $\mathrm{T}_{10}$, respectivamente). Os materiais abrasivos foram utilizados nos tratamentos $\left(\mathrm{T}_{2}, \mathrm{~T}_{3}\right.$ e $\left.\mathrm{T}_{4}\right)$ até a remoção da mucilagem. Fizeram-se as avaliações da percentagem do teor de água, utilizando-se de estufa a $105 \pm 3^{\circ} \mathrm{C}$, durante 24 horas (BRASIL, 2009), com 10 sementes para cada tratamento, em quatro repetições. $\mathrm{O}$ teste de germinação foi realizado em germinador tipo Biochemical Oxigen Demand (B.O.D.), em temperatura alternada de $20-30{ }^{\circ} \mathrm{C}$, com fotoperíodo de oito horas, utilizando-se de lâmpadas fluorescentes tipo luz do dia (4 x 20W). Para cada tratamento, foram utilizadas 25 sementes em quatro repetições, totalizando 100 sementes por tratamento. As sementes foram distribuídas sobre duas folhas de papel toalha umedecidas com água destilada, na quantidade equivalente a 2,5 vezes a massa do papel, seca, e, posteriormente, coberta com uma terceira folha de papel toalha umedecida. Estas foram amarradas em forma de rolos e acondicionadas 
em sacos plásticos, evitando perdas por evaporação. Fizeram-se as avaliações diariamente, sendo a primeira contagem de germinação a partir dos sete aos 15 dias após a instalação dos experimentos. Avaliaram-se o número e a percentagem de plântulas normais, apresentando raiz primária e parte aérea bem desenvolvidas.

$\mathrm{O}$ índice de velocidade de germinação foi determinado mediante contagens diárias do número de sementes germinadas, sempre no mesmo horário, dos sete aos 15 dias após a instalação do experimento, calculado de acordo com a fórmula proposta por Maguire (1962).

O comprimento e a massa seca das plântulas foram realizados após a contagem final do teste de germinação das plântulas normais de cada tratamento, medindo-se da raiz até o ápice caulinar, expressos em $\mathrm{cm}$ plântula ${ }^{-1}$, com auxílio de uma régua graduada em centímetros. As mesmas foram colocadas em sacos de papel Kraft e levadas à estufa por 48 horas, a $65^{\circ} \mathrm{C}$, até atingirem peso constante. Decorrido este período, foram pesadas, expressas em $\mathrm{g} /$ plântula $^{-1}$, em balança analítica com precisão de $0,001 \mathrm{~g}$.

O delineamento experimental utilizado foi o inteiramente ao acaso, em quatro repetições, e os dados foram submetidos à análise de variância, e as médias, comparadas pelo teste de Scott-Knott, a $5 \%$ de probabilidade.

\section{RESULTADOS E DISCUSSÃO}

Para a percentagem do teor de água nas sementes, o tratamento de lavagem em água com fricção em peneira $\left(\mathrm{T}_{6}\right)$ apresentou o maior valor, com $61 \%$, seguido da testemunha $\left(\mathrm{T}_{1}\right)$, com $42 \%$. Os demais tratamentos não diferiram estatisticamente, variando de 19 a 35\% (Figura 1). A elevação do teor de água no tratamento com lavagem das sementes em água com fricção em peneira $\left(\mathrm{T}_{6}\right)$ apresentou maior aderência da mesma com a mucilagem, devido à difícil retirada, o mesmo ocorrido com a testemunha da qual não se retirou a mucilagem.

Dessa forma, a presença da mucilagem nas sementes de $C$. tapia L. proporcionou maior percentagem de teor de água. Em Passiflora edulis f. flavicarpa Deg e Passiflora alata Curtis os maiores teores de água foram observados nas sementes com arilo apresentando (12,57 e 17,80 $\%$ ), respectivamente (MARTINS et al., 2006), e em a Talisia esculenta Radlk a redução no teor de água das sementes só foi possível quando houve retirada do material gelatinoso, as quais atingiram $(38,5 \%)$ de umidade após 96 horas de fermentação (ALVES et al., 2009).

A remoção da mucilagem das sementes de Punica granatum L. pelo método da fermentação apresentou um pequeno acréscimo no teor de água das sementes, em torno de $86 \%$ decorrente da exposição das sementes para maior hidratação (LOPES et al., 2001), o que de fato não foi o ocorrido para as sementes de $C$. tapia L., pois estas apresentam mucilagem cujo teor de água é elevado, como pode ser observado na testemunha $\left(\mathrm{T}_{1}\right)$; e à medida que esta é removida, ocorre redução do teor de água das sementes. A presença de mucilagem aderida ao tegumento das sementes não só influencia seu teor de água, como também impede sua utilização devido à presença de hormônios de crescimento, tais como etileno e ácido abscísico, os quais por sua vez, contribuem para a redução na germinação (TOKUHISA et al., 2007).

$\mathrm{Na}$ percentagem de germinação das sementes, houve diferença significativa entre os tratamentos. Os tratamentos de fricção em pó de madeira $\left(\mathrm{T}_{3}\right)$ e fermentação por 48 e 72 horas $\left(\mathrm{T}_{8}\right.$ e $\mathrm{T}_{9}$, respectivamente) proporcionaram as maiores percentagens de germinação $(91 ; 86$ e $89 \%)$. Nos tratamentos com fermentação por 24 e 96 horas $\left(\mathrm{T}_{7}\right.$ e $\mathrm{T}_{10}$, respectivamente), verificaram-se 81 e $79 \%$ de germinação, seguidas dos tratamentos de extração da mucilagem com fricção em cal $\left(\mathrm{T}_{2}\right)$ e areia $\left(\mathrm{T}_{4}\right)$, com 45 e $70 \%$ de germinação, respectivamente. Já o tratamento de lavagem das sementes com água e fricção em peneira $\left(\mathrm{T}_{6}\right)$ promoveu uma germinação de $35 \%$. De certa forma, a maioria dos tratamentos foi eficiente em promover uma germinação uniforme.

Não foi observada germinação nas sementes, nos tratamentos com mucilagem - testemunha $\left(\mathrm{T}_{1}\right)$ e secas ao sol (T5). A ausência de germinação nas sementes com mucilagem na testemunha $\left(\mathrm{T}_{1}\right)$ e com mucilagem e secas ao sol $\left(\mathrm{T}_{5}\right)$ deixa claro que ocorre uma resistência imposta pela camada mucilaginosa que envolve as sementes, e também a presença de substâncias inibidoras da germinação, as quais interferem de forma efetiva na absorção de água, impedindo, assim, os processos metabólicos necessários para a germinação das sementes. Pois a presença de moléculas hidrofóbicas, tais como os triglicerídeos ou a presença de esteroides, faz com que ocorra um desbalanço dos hormônios que promovem a germinação, o que foi constatado em trabalho realizado por Martins et al. (2010), quando utilizaram extratos do arilo de sementes de maracujáamarelo e verificaram a inibição da germinação de sementes de Lactuca sativa. Em sementes de Carica papaya L., observaram a presença de compostos fenólicos responsáveis pela diminuição 
na germinação e no vigor das sementes (TOKUHISA et al., 2007). A presença do arilo em sementes de Michelia champaca L., usadas por Candiani et al. (2004), também inibiu a germinação.

Quanto ao período de fermentação, as maiores porcentagens de germinação ocorreram com 48 e 72 horas, 86 e $89 \%$ ( $\mathrm{T}_{8}$ e $\mathrm{T}_{9}$, respectivamente) (Figura 2). Lopes et al. (2001) constataram que a fermentação por 72 horas foi responsável pela maior porcentagem de emergência das plântulas de Punica granatum L., assim como Alves et al. (2009) também obtiveram a maior porcentagem de emergência (93\%) de plântulas de Talisia esculenta Radlk após 76 horas de fermentação.

A percentagem de germinação na primeira contagem apresentou maiores valores nos tratamentos com fricção em pó de madeira $\left(\mathrm{T}_{3}\right)(90 \%)$, areia $\left(\mathrm{T}_{4}\right)$ $(77 \%)$ e fermentação por 48 horas $\left(\mathrm{T}_{8}\right)(80 \%)$. O percentual de germinação obtido nos tratamentos de fricção em cal $\left(\mathrm{T}_{2}\right)$ e fermentação, por 24; 72 e 96 horas $\left(\mathrm{T}_{7}, \mathrm{~T}_{9}\right.$ e $\mathrm{T}_{10}$, respectivamente), ficou em torno de $32 ; 59 ; 70$ e $63 \%$. Nas sementes com mucilagem $\left(T_{1}\right)$, com mucilagem e secas ao sol $\left(T_{5}\right)$, e nas sementes lavadas em água com fricção em peneira $\left(\mathrm{T}_{6}\right)$, não foi observada a germinação (Figura 3).

A determinação de métodos adequados para a remoção da mucilagem presente nas sementes de algumas espécies torna-se importante devido ao melhor desempenho das mesmas após sua remoção (CARVALHO; NAKAGAWA, 2012). Para as sementes de Coffea arabica L., os resultados de vigor evidenciaram efeito favorável da fermentação por um período aproximado de 48 horas, apresentando valores acima de 70\% (ARAÚJO et al., 1999).

No índice de velocidade de germinação das sementes, a extração da mucilagem com fricção em cal $\left(\mathrm{T}_{2}\right)$ e lavagem em água corrente com fricção em peneira $\left(\mathrm{T}_{6}\right)$ apresentou menores índices, em torno de 1,6 e 1,25. Os tratamentos com fricção em pó de madeira $\left(\mathrm{T}_{3}\right)$ e fermentação por 48 horas $\left(\mathrm{T}_{8}\right)$ apresentaram aceleração na germinação das sementes, com índices de 3,21 e 3,13, Não se observaram índices de velocidade de germinação nos tratamentos de sementes com mucilagem $\left(\mathrm{T}_{1}\right)$ e com mucilagem e secas ao sol ( $\left.\mathrm{T}_{5}\right)$ (Figura 4).

Gentil e Ferreira (2000) constataram em sementes de Eugenia stipitata ssp. sororia Mc Vaugh que a extração com fricção em cal, seguida da fricção em serragem apresentaram os maiores índices de velocidade de emergência. Em fermentação por 72 horas, os maiores índices de velocidade de emergência $(0,4)$ foram obtidos em plântulas de Punica granatum L. por Lopes et al. (2001). Todavia, em plântulas de Talisia esculenta Radlk, foram verificados maiores índices de velocidade de emergência após 104 horas de fermentação, com 1,66 (ALVES et al., 2009).

O comprimento das plântulas de C. tapia foram maiores que nos tratamentos com fricção em pó de madeira $\left(\mathrm{T}_{3}\right)$ e areia $\left(\mathrm{T}_{4}\right)(10,65$ e $10,26 \mathrm{~cm}$, respectivamente). Os tratamentos com fricção em cal $\left(\mathrm{T}_{2}\right)$, lavagem em água corrente com fricção em peneira $\left(\mathrm{T}_{6}\right)$ e fermentação por 24 e 72 horas $\left(\mathrm{T}_{7}\right.$ e $\mathrm{T}_{9}$, respectivamente) apresentaram, em média, 4,97; 6,0 e $6,12 \mathrm{~cm}$ de comprimento de plântulas. De forma geral, o melhor resultado ficou com o tratamento com fricção em pó de madeira $\left(\mathrm{T}_{3}\right)$, o qual foi eficiente na remoção da mucilagem, mas preservou a qualidade das sementes, pois foi o método que proporcionou os melhores resultados nas variáveis analisadas.

A fermentação de sementes de Passiflora edulis Sims f. flavicarpa Deneger influenciou positivamente o comprimento da raiz pivotante das plântulas resultantes (CARDOSO et al., 2001). Nas sementes de Talisia esculenta Radlk, a remoção da mucilagem também favoreceu o comprimento das plântulas, registrando-se o maior valor $(26,49$ $\mathrm{cm})$ quando as mesmas ficaram em processo de fermentação por 86 horas (ALVES et al., 2009).

A massa seca das plântulas de C. tapia L. variou entre 0,0375 gramas e 0,632 gramas, sendo os tratamentos extração com fricção em pó de madeira $\left(\mathrm{T}_{3}\right)$ e fermentação por 48 horas $\left(\mathrm{T}_{8}\right)$ responsáveis pelos maiores valores de massa seca de plântulas (Figura 6). Em estudos com plântulas de maracujá, o conteúdo de massa seca não foi influenciado pelos diferentes períodos de fermentação das sementes (CARDOSO et al., 2001); o mesmo não foi observado no presente trabalho, onde se verificou que a fermentação por tempo inferior ou superior a 48 horas afetou o conteúdo de massa seca das plântulas de C. tapia L., conforme ocorreu em plântulas de Talisia esculenta Radlk, onde o conteúdo de massa seca apresentou variações com o período de fermentação, sendo os maiores valores $(0,270 \mathrm{~g})$ obtidos em 105 horas de fermentação (ALVES et al., 2009). 
TABELA 1 - Teor de agua, germinação e primeira contagem de germinação de sementes de Crataeva tapia L. submetidas a diferentes métodos para a extração da mucilagem.

\begin{tabular}{c|c|c|c}
\hline Tratamentos & Teor de água (\%) & Germinação (\%) & Primeira contagem (\%) \\
\hline T1 & $42,47 \mathrm{~b}$ & $0 \mathrm{f}$ & $0 \mathrm{~d}$ \\
T2 & $23,88 \mathrm{c}$ & $45 \mathrm{~d}$ & $32 \mathrm{c}$ \\
T3 & $29,84 \mathrm{c}$ & $91 \mathrm{a}$ & $90 \mathrm{a}$ \\
T4 & $19,54 \mathrm{c}$ & $70 \mathrm{c}$ & $77 \mathrm{a}$ \\
T5 & $25,82 \mathrm{c}$ & $0 \mathrm{f}$ & $0 \mathrm{~d}$ \\
T6 & $61,11 \mathrm{a}$ & $35 \mathrm{e}$ & $0 \mathrm{~d}$ \\
T7 & $31,74 \mathrm{c}$ & $81 \mathrm{~b}$ & $59 \mathrm{~b}$ \\
T8 & $34,89 \mathrm{c}$ & $86 \mathrm{a}$ & $80 \mathrm{a}$ \\
T9 & $22,25 \mathrm{c}$ & $89 \mathrm{a}$ & $70 \mathrm{~b}$
\end{tabular}

Médias seguidas de mesma letra, mesma letra na colun não diferem estatisticamente entre si, pelo teste de Scott-Knott, a 5\% de probabilidade.

Testemunha $\left(\mathrm{T}_{1}\right)$, fricção em cal, pó de madeira e areia $\left(\mathrm{T}_{2}, \mathrm{~T}_{3}\right.$ e $\mathrm{T}_{4}$, respectivamente), secagem ao sol $\left(\mathrm{T}_{5}\right)$, lavagem em água corrente com fricção em peneira $\left(\mathrm{T}_{6}\right)$, fermentação por $24 ; 48 ; 72$ e 96 horas $\left(\mathrm{T}_{7}, \mathrm{~T}_{8}, \mathrm{~T}_{9}, \mathrm{~T}_{10}\right.$, respectivamente).

TABELA 2 - Índice de velocidade de germinação (IVG), comprimento de plântulas (cm) e massa seca de plântulas (g), oriundas de sementes de Crataeva tapia L. submetidas a diferentes métodos para extração da mucilagem.

\begin{tabular}{ccccc}
\hline Tratamentos & IVG & Comprimento de plântulas & Massa de plântulas \\
\hline T1 & $0 \mathrm{e}$ & $0 \mathrm{e}$ & $0 \mathrm{e}$ \\
T2 & $1,6 \mathrm{~d}$ & $4,97 \mathrm{~d}$ & $0,0675 \mathrm{e}$ \\
T3 & $3,21 \mathrm{a}$ & $10,65 \mathrm{a}$ & $0,575 \mathrm{a}$ \\
T4 & $2,77 \mathrm{~b}$ & $10,26 \mathrm{a}$ & $0,335 \mathrm{c}$ \\
T5 & $0 \mathrm{e}$ & $0 \mathrm{e}$ & $0 \mathrm{e}$ \\
T6 & $1,25 \mathrm{~d}$ & $6 \mathrm{c}$ & $0,0375 \mathrm{e}$ \\
T7 & $2,87 \mathrm{~b}$ & $6,3 \mathrm{c}$ & $0,272 \mathrm{~d}$ \\
T8 & $3,13 \mathrm{a}$ & $9,65 \mathrm{~b}$ & $0,632 \mathrm{a}$ \\
T9 & $2,49 \mathrm{c}$ & $6,12 \mathrm{c}$ & $0,382 \mathrm{~b}$ \\
T10 & $2,29 \mathrm{c}$ & $9,32 \mathrm{~b}$ & $0,435 \mathrm{~b}$
\end{tabular}

Médias seguidas de mesma letra, mesma letra na coluna não diferem estatisticamente entre si, pelo teste de Scott-Knott, a $5 \%$ de probabilidade.

Testemunha $\left(\mathrm{T}_{1}\right)$, fricção em cal, pó de madeira e areia $\left(\mathrm{T}_{2}, \mathrm{~T}_{3}, \mathrm{e} \mathrm{T}_{4}\right.$, respectivamente, secagem ao sol $\left(\mathrm{T}_{5}\right)$, lavagem em água corrente com frição em peneira ( $\left.\mathrm{T}_{6}\right)$, fermentação por 24; 48; 72 e 96 horas ( $\mathrm{T}_{7}, \mathrm{~T}_{8} . \mathrm{T}_{9}, \mathrm{~T}_{10}$, respecitivamente). 


\section{CONCLUSÕES}

A presença de mucilagem nas sementes de Crataeva tapia L. inibe totalmente a germinação, pois a percentagem do teor de água nas mesmas mantém-se mais elevado.

Os métodos de extração da mucilagem com fricção em pó de madeira e fermentação por 48 e 72 horas são os mais eficientes na remoção da mucilagem das sementes de C. tapia.

\section{REFERÊNCIAS}

ALVES, C.Z.; GODOY, A.R.; OLIVEIRA, N.C. Efeito da remoção da mucilagem na germinação e vigor de sementes de Hylocereus undatus Haw. Revista Brasileira de Ciências Agrárias, Recife, v.7, n.4, p.586-589, 2012.

ALVES, E.U.; SILVA, K.B.; GONÇALVES, E.P.; CARDOSO, E.A.; ALVES, A.U. Germinação e vigor de sementes de Talisia esculenta (St. Hil) Radlk em função de diferentes períodos de fermentação. Semina: Ciências Agrárias, Londrina, v.30, n.4, p.761-770, 2009.

ARAÚJO, E.F.; ARAÚJO, R.F.; SILVA, R.F.; GOMES, J.M. Efeitos imediatos e latentes do período de fermentação na qualidade de sementes de café (Coffea arabica L.). Revista Brasileira de Sementes, Londrina, v.21, n.2, p.238-242, 1999.

BRASIL. Ministério da Agricultura, Pecuária e Abastecimento. Regras para análise de sementes. Brasília: Secretaria de Defesa Agropecuária, 2009. $395 p$.

CANDIANI, G.; GALETT. I.M.; CARDOSO, V.J.M. Seed germination and removal of Michelia champaca L. (Magnoliaceae) in eucalypt stands: the influence of the aril. Revista Árvore, Viçosa, MG, v.8, n.3, p.327-332, 2004.

CARDOSO, G.D.; TAVARES, J.C.; FERREIRA, R.L.F.; CÂMARA, F.A.A.; CARMO, G.A. Desenvolvimento de mudas de maracujazeiroamarelo obtidas de sementes extraídas por fermentação. Revista Brasileira de Fruticultura, Jaboticabal, v.23, n.3, p.639-642, 2001.
CARMONA, R.; REZENDE, L.P.; PARENTE, T.V. Extração química de sementes de gabiroba (Campomanesia adamantium Camb.). Revista Brasileira de Sementes, Viçosa, MG, v.16, n.1, p.31-33, 1994.

CARVALHO, N.M.; NAKAGAWA, J. Sementes: ciência, tecnologia e produção. 5.ed. Jaboticabal: FUNEP, 2012. 590p.

FREITAS, S.J.; BARROSO, D.G.; SILVA, R.F.; MARTINS, V.H.C.R.; FREITAS, M.D.S.; FERREIRA, P.R. Métodos de remoção da sarcotesta na germinação de sementes de jaracatiá. Revista Árvore, Brasília, DF, v.35, n.1, p.91-96, 2011.

GENTIL, D.F.O.; FERREIRA, S.A.N. Métodos de extração e limpeza de sementes de araçá-boi (Eugenia stipitata ssp. sororia). Acta Amazonica, Manaus, v.30, n.1, p.23-30, 2000.

KOHAMA, S.; MALUF, A.M.; BILIA, D.A.C.; BARBEDO, C.J. Secagem e armazenamento de sementes de Eugenia brasiliensis Lam. (grumixameira). Revista Brasileira de Sementes, Pelotas, v.28, n.1, p.72-78, 2006.

LOPES, K.L.; BRUNO, R.L.A.; BRUNO, G.B.; AZEREDO, G.A. Comportamento de sementes de romã (Punica granatum L.) submetidas à fermentação e secagem. Revista Brasileira de Fruticultura, Jaboticabal, v.23, n.2, p.369-372, 2001.

LORENZI, H. Árvores brasileiras: manual de identificação e de cultivo de plantas arbóreas do Brasil. 4.ed. São Paulo: Nova Odessa, 2002. 368p.

MAGUIRE, J.D. Speed of germination aid in selection and evaluation for seedling emergence and vigor. Crop Science, Madison, v.2, n.2, p.176-177, 1962.

MARTINS,C.M.; BARROS, C.S.; VASCONCELLOS, M.A.S.; ROSSETTO, C.A.V. Qualidade sanitária das sementes de maracujá-amarelo e maracujá-doce submetidas a diferentes métodos de preparo. Agronomia, Itaguaí, v. 40, n.1-2, p.35-39, 2006. 
MARTINS, C.M.; VASCONCELLOS, M.A.S.; ROSSETTO, C.A.V.; CARVALHO, M.G. Prospecção fotoquímica do arilo de sementes de maracujáamarelo e influência em germinação de sementes. Ciência Rural, Santa Maria, v.40, n.9, p.1934-1940, 2010 .

OSIPI, E.A.F.; LIMA, C.B.; COSSA, C.A. Influência de métodos de remoção do arilo na qualidade fisiológica de sementes de Passiflora alata Curtis. Revista Brasileira de Fruticultura, Jaboticabal, p.680-685, 2011. Volume especial.
PRATISSOLI, D.; POLANCZYK, R.A.; DALVI, L.P.; COCHETO, J.G.; MELO, D.F. Ocorrência de Ascia monusteorseis (Lepidoptera: Pieridae) danificando mudas de Crataeva tapia. Ciência Rural, Santa Maria, v.37, n.3, p.874-875, 2007.

TOKUHISA, D.; DIAS, D.C.F.S.; ALVARENGA, E.M.; HILST, P.C.; DEMUNER, A.J. Compostos fenólicos inibidores da germinação em sementes de mamão (Carica papaya L.). Revista Brasileira de Sementes, Viçosa, MG, v.29, n.3, p.180-188, 2007. 